\title{
Zigbee and RFID Based Student Attendance Monitoring System with Energy Saving
}

\author{
Bhingude Kisan ${ }^{1}$, Bhise S.K ${ }^{2}$ \\ Student E\&TC Department, Dr. Daulatrao Aher College of Engineering, Karad,India ${ }^{1}$ \\ Assistant Prof. E\&TC Department, Dr. Daulatrao Aher College of Engineering, Karad, India ${ }^{2}$
}

\begin{abstract}
In today's world the use of RFID technology is increased in the fields like health-care, transportation, agriculture, and hospitality- industry because of most popularity of RFID technology. In our project the main purpose is that, to save the valuable time and energy required for maintaining attendance records of students. Attendance Monitoring System by Using Zigbee and RFID technology are designed to collect and manage student's attendance record from RFID devices installed in an educational institute. After the verification of the student identification in the classroom, the system could generate simplified student attendance database for analysis purpose in schools or collages. The RFID system consists of an RFID tag, reader and a user interface computer. When the RFID tag is activated by the Radio Frequency field, then it transmits back the identification contents stored in memory by modulating the incoming Radio Frequency field. The reader detects and demodulates the signal and identifies the tag shown by teacher or student. Objective of our project is to install proposed system in colleges or schools which help to element the wastage of time taken by manual attendance system. The major problem faced by whole world is unnecessary use of energy devices which causes wastage of energy; our project is going to solve this problem by add-on energy saving system.
\end{abstract}

Keywords: Energy saving system, IR Module \& Attendance Monitoring System, Zigbee, RFID.

\section{INTRODUCTION}

The major difficulty faced by schools and colleges is time consuming manual attendance; the attendances are recorded manually by the teacher and therefore are prone to personal errors. There arises a need of more useful as well as effective methods for to overcome this problem. This problem is solved by today's most popular RFID technology. RFID technology is used for identification of tags and data collection purpose. RFID is not actually a new technology; it only quickly gained more attention recently because of its low cost and advances in other computing technology that opens up more application fields. RFID becomes radio RF and microchip technologies to create a smart system that can be used to verify, monitoring, secure and to do objects inventory.[1] At their simplest, RFID systems use tiny chips called -tags that contain and transmits some data for verify information to an RFID reader, a device that is interfaced with computers [4]. In today's life energy saving is become a one of the most need. So we made an automated energy saving system which is very useful for that. In that a simple IR module is used to sense a presence and absence of human in room and according to that system keep ON or OFF energy consumptions devices like Fan, Lights etc.

\section{LITERATURE REVIEW}

In paper [2] Attendance Monitoring System Using Zigbee and RFID are designed to collect and manage student's attendance record from RFID devices installed in an educational environment. Based on the identification of the student in the class, the system could generate simplified student attendance database for analysis purpose. Student's attendance automation is based on personal profile. Students or teacher profile can be edited any time without making changes in the hardware. In the RFID system contains RFID tags, reader and a user interface computer. When the RFID tag is activated by the Radio Frequency field, then it transmits back the identification contents stored in memory by modulating the incoming Radio Frequency field. The RFID reader identifies and demodulates the signal and recognizes the tag.

In this paper [3], try to solve today's lecture attendance monitoring problem in developing countries using RFID technology. The application of RFID to student attendance monitoring as developed and deployed in this study is capable of eliminating time wasted during manual collection of attendance and an opportunity for the educational administrators to identify every classroom analysis for allocation of proper attendance scores and for further management decisions.

In our project the attendance monitoring using Zigbee and rfid is somehow same but the new concept in our project is that energy saving function. In that the bidirectional IR sensor detect the presence and absence of human in room and turn ON or OFF energy devices like FAN, LIGHT etc.

\section{A. Energy Saving System}

Often we see visitor counters at stadium, mall, offices, class rooms etc. In that the bidirectional IR sensor detect the presence and absence of human in room and turn ON or OFF energy devices like FAN, LIGHT etc. 
IARJSET

\section{Sensor section}

We have used two IR sensor modules which have IR diodes, potentiometer, Comparator (Op-Amp) and LED's. Potentiometer is nothing but variable resister used for vary reference voltage at comparator's one terminal and IR sensors sense the object or person and provide a change in voltage at comparator's second terminal. After that comparator compares both output voltages and generates a proper digital signal at output. In this circuit we use two comparators for two different sensors. LM358 IC is used as a comparator. LM358 IC contains two low noise Opamp.

\section{Control Section}

Arduino controller is used for controlling whole the process of this visitor counter circuitry. The outputs of comparators are connected to digital pin of arduino. Arduino controller read the IR output signals and sends commands to relay driver circuitry to drive the relay for controlling applications.

\section{Display section}

In this section contains a $16 \times 2$ LCD. Display shows the number of counted people and light status when no one in the classroom.

\section{Relay Driver section}

Relay driver circuitry consist a BC547 transistor and a 230 volt relay for controlling the application. Transistor is used to drive the relay because arduino controller does not have enough voltage and current to drive relay circuitry. So we added a relay driver circuitry to get required voltage and current for relay. Arduino controller sends commands to this relay driver BC547 transistor and then application will turn on/off accordingly.

\section{B. Attendance Monitoring System \\ 1. RFID Reader}

Radio-frequency identification

electromagnetic fields to automatically identify and track tags attached to objects. The tags contain electronically stored information. Passive tags collect energy from a nearby RFID reader's interrogating radio waves. Active tags have a local power source such as a battery and may operate at hundreds of meters from the RFID reader. Unlike a barcode, the tag need not be within the line of sight of the reader, so it may be embedded in the tracked object. RFID is one method for Automatic Identification and Data Capture (AIDC) [1].

\section{Read the RFID Tag by Controller section}

Suppose students are enter into a classroom then they will show its identification card to that rfid reader system then RFID Reader will read the RFID tag and Check if it relates to teacher or student. After that It will also display the Tag information using the $16 \times 2$ LCD Display. Suppose the showing tag is of master then it will start transmitting the
RFID tag information or else it will wait for the teacher to punch the it's rfid tag and also display the card when it's punched [7].

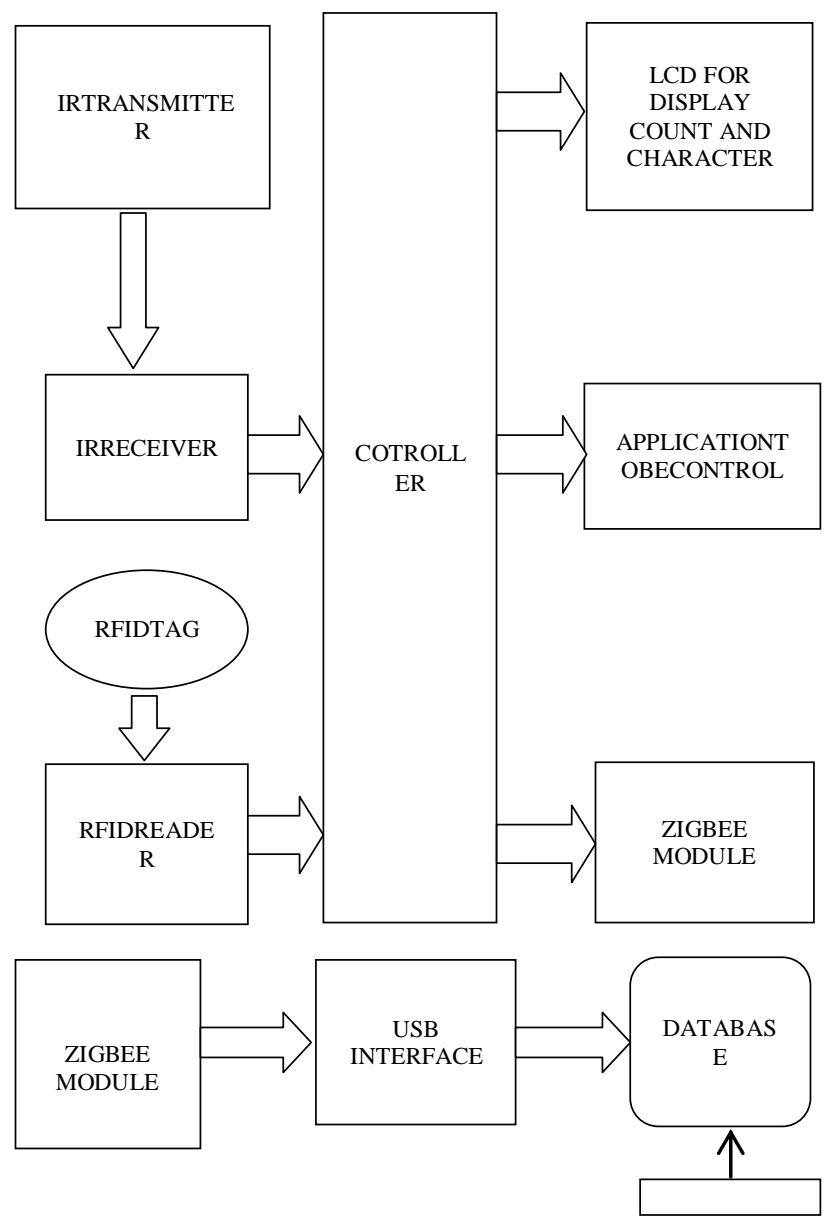

Fig 1. Functional Block Diagram

\section{Controller}

The Arduino Uno is a microcontroller board based on the ATmega328 (datasheet). It has 14 digital input/output pins (of which 6 can be used as PWM outputs), 6 analog inputs, a $16 \mathrm{MHz}$ ceramic resonator, a USB connection, a power jack, an ICSP header, and a reset button. It contains everything needed to support the microcontroller; simply connect it to a computer with a USB cable or power it with an AC-to-DC adapter or battery to get started. The Uno differs from all preceding boards in that it does not use the FTDI USB-to-serial driver chip [8].

Arduino features

$\begin{array}{lll}\text { - } & \text { Microcontroller } & \text { ATmega328 } \\ \text { - } & \text { Operating Voltage } & 5 \mathrm{~V} \\ \text { - } & \text { Input Voltage (recommended) } & 7-12 \mathrm{~V} \\ \text { - } & \text { Digital I/O Pins } & 14 \\ \text { - } & \text { Analog Input Pins } & 6 \\ \text { - } & \text { DC Current per I/O Pin } & 40 \mathrm{~mA} \\ \text { - } & \text { Flash Memory } & 32 \mathrm{~KB}(\mathrm{ATmega328}) \\ \text { - } & \text { Clock Speed } & 16 \mathrm{MHz}\end{array}$


IARJSET

\section{Zigbee Transmitter \& Receiver}

Zigbee is a wireless networking technology designed for reliable, power-efficient, and low-latency communications between low-cost nodes. Zigbee was created in order to fill a void in the area of wireless monitoring and control for various commercial applications. Other protocols such as $802.11 \mathrm{~b}$ and Bluetooth either wastes a significant amount of power or is overly complicated for simple automation tasks. Zigbee provides a low bandwidth alternative that can transmit simple instructions while conserving power to further the time the unit can operate off battery power before needing to be recharged. This technique allows small devices like sensors to operate efficiently while providing all necessary functionality for the specific application in which it is deployed. ZigBee and IEEE 802.15.4 are standards-based protocols that provide the network infrastructure required for wireless sensor network applications [6].

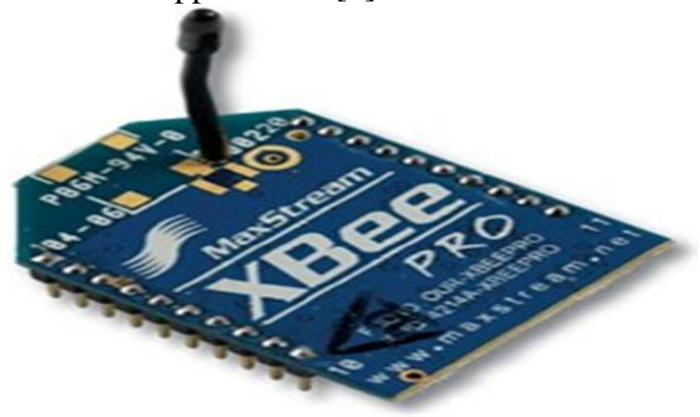

Fig 2. Zigbee

TABLE-I Zigbee Feature

\begin{tabular}{|c|c|c|}
\hline Parameters & XBee & XBee-PRO \\
\hline Range - Indoor & $100 \mathrm{ft}(30 \mathrm{~m})$ & $300 \mathrm{ft}(100 \mathrm{~m})$ \\
\hline Range - Outdoor & $\begin{array}{c}300 \mathrm{ft} \\
(100 \mathrm{~m})\end{array}$ & $\begin{array}{c}1 \mathrm{mile} \\
(1500 \mathrm{~m})\end{array}$ \\
\hline Transmit Power & $\begin{array}{c}0 \mathrm{dBm} \\
(1 \mathrm{~mW})\end{array}$ & $\begin{array}{c}20 \mathrm{dBm} \\
(100 \mathrm{~mW})\end{array}$ \\
\hline Receiver Sensitivity & $-92 \mathrm{dBm}$ & $-100 \mathrm{dBm}$ \\
\hline $214 \mathrm{Ma}$ & TX Current & $45 \mathrm{~mA}$ \\
\hline RX Current & $50 \mathrm{~mA}$ & $55 \mathrm{~mA}$ \\
\hline $\begin{array}{c}\text { Power-Down (Sleep) } \\
\text { Current }\end{array}$ & $<10 \mathrm{uA}$ & $<10 \mathrm{uA}$ \\
\hline
\end{tabular}

5. Receiver Section

At The Receiver section a Zigbee module is connected to personal computer by using TTL to USB converter to Store the Data.

6. Requirement of software for Data Base

- Windows: Operating system

- $\quad$ Microsoft Access: Database to store attendance

- $\quad$ VB 6.0 :To Receive data using comp port

\section{IV.WORKING PRINCIPLE}

\section{Read Tag Using Arduino Controller}

- $\quad$ Student or Teacher come into room throughout bidirectional visitor counter circuitry which making the sense to presence of person in room for energy saving system.

- $\quad$ RFID Reader will read the RFID tag and Check if it relates to teacher or student.

- The information about that particular showing tag will be also displayed on 16x2 displays.

- Suppose the showing tag is of Teacher then control section will start to transmit the tag numbers of present students to database system using transmitter Zigbee module.

\section{Database Management}

- The data is received by receiver Zigbee module and it is serially connected to the computer.

- Visual Basicis a tool that allows you to develop Windows (Graphic User Interface - GUI) applications. The applications have a familiar appearance to the user.

- Using GUI we can see all information about student like id number, name, and attendance and also we can register a new student.

- All the data belongs to student attendance, subject, time, id no. is store in computer in excel sheet

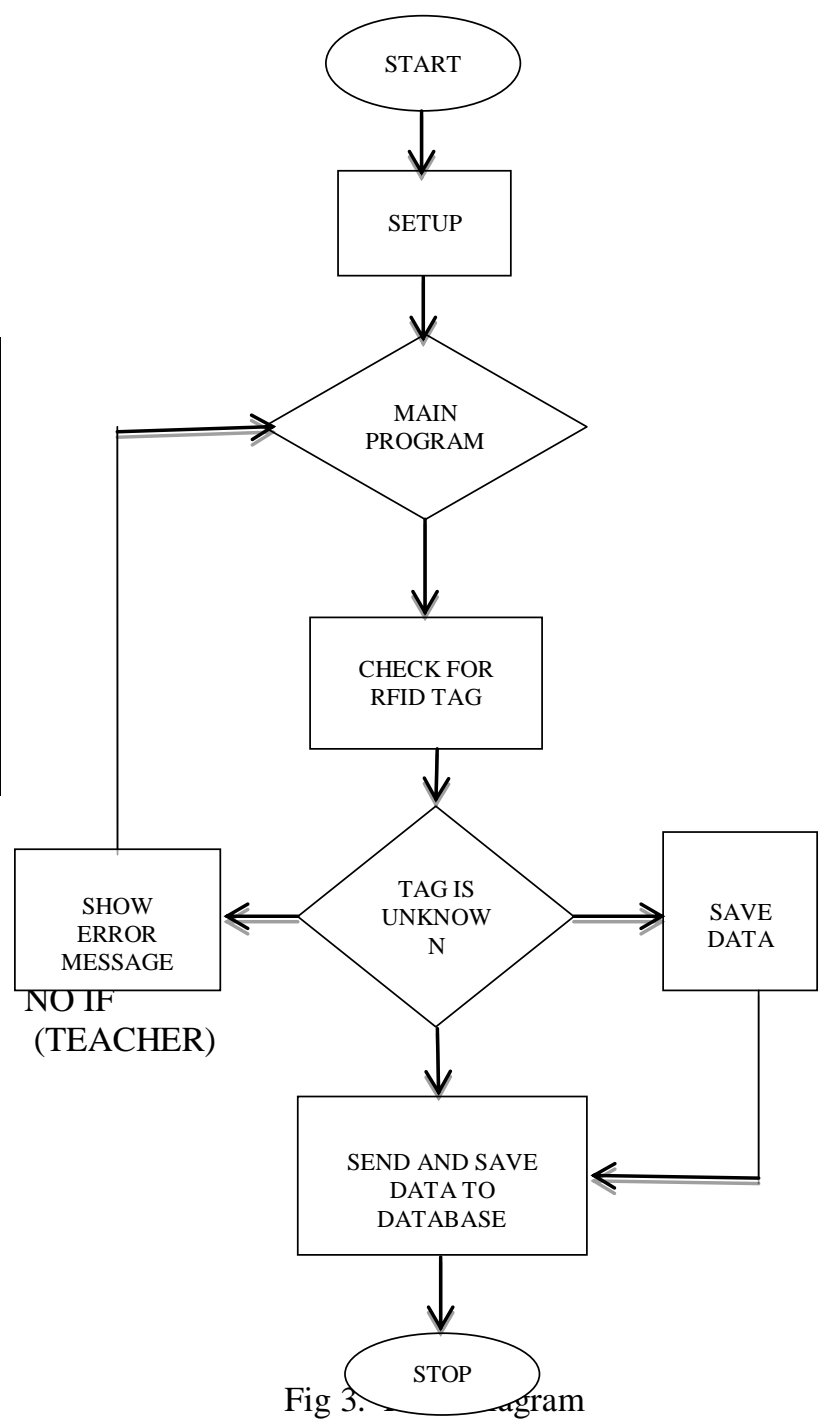




\section{CONCLUSIONS}

In our system the student ID card is replaced by specific RFID tag, so our system is very helpful to save valuable time taken for student attendance and also save the paper required for student attendance record. And also this system will improve attendance of chronically absent or truant students in order to provide them with an opportunity to improve their academic achievement and social development. The system is also save our valuable energy.

\section{VI.LIMITATIONS AND FUTURE SCOPE}

Because of no line of sight communication the Zigbee gives range of communication is less than 100 meters, so repeaters are require. By adding GSM module in this project, we send a data about student through message to its parents. We can also add the features like Interactive Voice Response System (IVRS).

\section{ACKNOWLEDGMENT}

We would like to thank sincerely to our guide Prof. S.K.Bhise and thank him for his endless support and motivation for his invaluable guidance, constant assistance, support, endurance and constructive suggestions for the betterment of this project work.

\section{REFERENCES}

[1] RFID Overview: Introduction to Radio Frequency Identification by Intermec Technologies Corporation.

[2] Aslam Khan, Akshay Patil, Viral Shah and Mansi Kambli "Attendance Monitoring System Using ZigBee and RFID" International Journal For Research In Emerging Science And Technology, Volume-2, Issue-2, February-2015

[3] Arulogun O. T., Olatunbosun, A., Fakolujo O. A., and Olaniyi, O. M. "RFID-Based Students Attendance Management System" International Journal of Scientific \& Engineering Research Volume 4, Issue 2, February-2013

[4] Dawes A.T. (2004),"'Is RFID Right for Your Library", Journal of Access Services, Volume 2(4), pp 7 -

13.

[5] http://rfidguardian.org

[6] http://science.smith.eduen.wikipedia.org

[7] http://en.wikipedia.org

[8] http://emchrosystems.com 